\title{
Extrato de neem no tratamento de sementes de tomate
}

\section{Neem extract for tomato seeds treatment}

\section{Leomara Vieira de França Cardozo ${ }^{1}$; Moisés Vieira Pinhão Neto ${ }^{2}$}

${ }^{1}$ Doutora em Ciências, Universidade Estadual do Piauí, Professora Adjunta III do Curso de Agronomia, Corrente; (89) 999395150, agro_leomara@yahoo.com.br; ${ }^{2}$ Engenheiro Agrônomo pela Universidade Estadual do Piauí, Autônomo, Barreiras do Piauí; (89) 981063778, moisesvieirapn@gmail.com

\section{A R T I G O}

Recebido: $25 / 05 / 2018$

Aprovado: $17 / 12 / 2018$

Publicado: 01/01/2019

\section{Palavras-chave:}

Azadirachta indica

Solanum lycopersicum L.

Fisiologia

Sanidade
Key words:

Azadirachta indica

Solanum lycopersicum L.

Physiology

Sanity

\section{R E S U M O}

Os sistemas de produção orgânica devem ser implantados utilizando sementes orgânicas livres de microrganismos e sem utilizar produtos químicos. Extratos de neem têm apresentado eficiência no controle de microrganismo, porém o efeito do neem na qualidade fisiológica das sementes tratadas por ele é pouco conhecido. Objetivou-se, no presente trabalho, propor extrato aquoso de folha de neem, alternativo ao tratamento químico de semente de tomate cultivar Super Marmande. O experimento foi realizado na Universidade Estadual do Piauí campus Corrente. Produziram-se diferentes concentrações de extrato aquoso de neem utilizando $0,40,80,120,160$ e $200 \mathrm{~g}$ de folha para cada $\mathrm{L}$ de água destilada. Doses de cada concentração contendo $8 \mathrm{ml}$ do extrato aquoso foram utilizadas para tratar 100 sementes de tomate, além da dose de Thiran utilizando 3 gramas por quilo de semente (testemunha químico). Após tratadas as sementes foram submetidas às avaliações de germinação, primeira contagem da germinação, frio, emergência a campo, índice de velocidade de emergência, matéria seca das plântulas e índice de frequência de contaminantes. Utilizou-se o delineamento inteiramente ao acaso com 7 tratamentos em 4 repetições. Nenhuma das concentrações com extratos aquosos de folha de neem alteraram a qualidade fisiológica das sementes de tomate, porém apenas as concentrações contendo 160 e $200 \mathrm{~g} \mathrm{~L}^{-1}$ foram eficientes na redução de contaminantes presentes nas sementes. Diante dos dados obtidos recomenda-se para o tratamento orgânico de sementes de tomate utilizar extrato aquoso de neem nas concentrações entre 160 e $200 \mathrm{~g} \mathrm{~L}^{-1}$ como alternativa ao tratamento químico.

\section{A B S T R A C T}

Organic production systems should be implanted using organic seeds free of microorganisms and without chemicals application. Neem extracts has been shown to be efficient to control seed microorganism, however its effects on the physiological seed quality, is still unknown. The aim of this work was to identify the viability of aqueous extract of neem leaf as an alternative to the chemical treatment in tomato seeds Super Marmande cultivar. The experiment was carried out in a laboratory of the State University of Piauí campus Corrente. Different concentrations of neem aqueous extract were prepared using $0,40,80,120,160$ and 200 grams of neem leaves per 1 liter of distilled water. Doses of each concentration containing $8 \mathrm{ml}$ of the aqueous extract were used to treat 100 tomato seeds. A dose of thiran (3 grams per kilogram of seed) was used as chemical control. After the treatment, seeds were evaluated for germination, first counting of germination, cold, field seed emergence, emergence speed index, dry matter of seedlings and frequency index of contaminants. For this study a completely randomized design was emplyed, with 7 treatments and 4 replicates. None of the neem aqueous extracts concentrations altered physiological quality of tomato seeds. Moreover, the neem extracts with a concentration of 160 and $200 \mathrm{~g} \mathrm{~L}^{-1}$ were efficient to reduce contaminants present in the seeds. Based on our results, the application of neem extracts could be an efficient alternative for organic treatment of tomato seeds replacing chemical treatments.

\section{Revista Verde}

ISSN 1981-8203

Pombal, Paraíba, Brasil v. 14, n.1, jan.-mar, p.01-04, 2019 doi: $10.18378 /$ rvads.v14i1.5772 


\section{INTRODUÇÃO}

Nos sistemas de produção agrícola a qualidade das sementes é essencial para garantir produtividade satisfatória. Dentre os componentes que expressam qualidade, a sanidade se destaca, pois microrganismos como fungos, bactérias, vírus e nematoides se refugiam na superfície ou no interior das sementes, podendo transmitir doenças que causam deterioração, comprometem a germinação, além de reduzir vigor e consequentemente o rendimento da cultura.

Sementes de tomate (Solanum lycopersicum L.) podem abrigar e/ou transmitir vários patógenos como Fusarium oxysporum f.sp. lycopersici e f.sp. redolens; Alternaria solani; Cladosporium spp.; Clavibacter michiganensis subsp. Michiganensi; Sclerotinia sclerotiorum; Xanthomonas campestres pv. vesicatoria; e Tabacco mosaic virus (LOPES, 2014). Neste sentido, tratamentos químicos, físicos, biológicos ou a combinação destes tem sido bastante utilizado com intuito de erradicar patógenos em sementes, sendo o químico mais eficiente. Na cultura do tomate os princípios ativos químicos mais utilizados em sementes são o Thiran e o Captan (MELO et al., 2014).

Os sistemas orgânicos vegetais deveriam ser oriundos de sementes orgânicas com ausência de agrotóxicos químicos desde dezembro de 2013 (BRASIL, 2008). Entretanto, como o sistema sementeiro não conseguiu nesse prazo suprir o mercado com $100 \%$ de sementes orgânicas, esse tempo determinado foi alterado para 2016, sendo que a partir desse ano a Comissão de Produção Orgânica de cada Unidade da Federação poderá produzir anualmente uma lista com as espécies e variedades com sementes orgânicas existentes, e as demais podem continuar utilizando sementes convencionais nos sistemas orgânicos (BRASIL, 2014).

Tanto as sementes orgânicas quanto as convencionais, a serem utilizadas no sistema orgânico devem ser livres de agrotóxicos, havendo a necessidade de utilizar no tratamento dessas sementes produtos naturais, alternativos aos químicos, para reduzir ou eliminar os patógenos sem prejudicar a qualidade fisiológica das sementes (germinação e vigor).

Uma alternativa natural seria a utilização de extrato de neem (Azadirachta indica), pois além de agir como inseticidas, também tem apresentado efeito positivo na redução do inóculo de fungos em sementes de arroz (AMADIOHA, 2000), girassol (CHATTOPADHY, 1999), tomate (AMADIOHA; UCHENDU, 2003), amendoim (BHONDE et al., 1999) e milho (OWOLADE et al., 2000).

Com base nisso, este trabalho teve como objetivo propor extrato aquoso de folha de neem, alternativo ao químico no tratamento de semente de tomate cultivar Super Marmande.

\section{MATERIAL E MÉTODOS}

O trabalho foi conduzido no Laboratório de Análise de Sementes (LAS) da Universidade Estadual do Piauí, no Campus Dep. Jesualdo Cavalcanti Barros, na cidade de Corrente, Piauí. A partir de plantas em estágio vegetativo de neem cultivadas em Corrente, foram coletadas folhas do terço inferior, em junho de 2017, lavadas em água corrente. Foram produzidas 6 concentrações de extratos utilizando $0,40,80$, 120,160 e $200 \mathrm{~g}$ de folha trituradas em $1 \mathrm{~L}$ de água destilada em liquidificador, na velocidade mais baixa pelo período de 2 min (RICKLI et al., 2011). Após o processo de trituração, as soluções (folha triturada + água destilada) de cada concentração permaneceram em repouso por $24 \mathrm{~h}$ a temperatura ambiente do LAS, em copos plásticos com a boca fechada com papel alumínio, sendo após esse período filtrado em papel filtro (100\% fibras celulósicas) para obtenção dos extratos aquosos nas respectivas concentrações.

Os tratamentos foram realizados em semente de tomate de mesa da cultivar Super Marmande nas concentrações 0, 40, $80,120,160$ e $200 \mathrm{~g} \mathrm{~L}^{-1}$ de extrato aquoso da folha de neem, além do produto comercial Thiran utilizado como testemunha químico. Para cada concentração de extrato foram colocadas em sacos plásticos doses de $8 \mathrm{ml}$ de extrato aquoso para 100 sementes, e para a testemunha química utilizou-se $3 \mathrm{~g}$ de Thiran por kg de semente (ROSSETTO et al., 2001). Agitouse manualmente as sementes com os respectivos tratamentos por 2 min e na sequência submeteu as sementes às avaliações de germinação, primeira contagem da germinação, teste de frio, emergência a campo, índice de velocidade de emergência, matéria seca das plântulas, índice da frequência de microrganismos.

Na germinação utilizou-se 100 sementes por tratamento, sendo distribuídas em papel germitest na forma de rolo umedecido com água destilada na proporção de 2,5 vezes o peso do papel e então acondicionadas em germinador tipo BOD à temperatura alternada de $20^{\circ} \mathrm{C}$ por $8 \mathrm{~h}$ e $30^{\circ} \mathrm{C}$ por 16 h. A avaliação foi realizada 14 dias após a implantação do teste, sendo o resultado expresso em porcentagem de plântulas normais (BRASIL, 2009b).

A primeira contagem da germinação foi realizada concomitante com o teste de germinação, sendo avaliadas as sementes que apresentavam emissão de radícula no quinto dia após a instalação do teste, com resultado expresso em porcentagem (BRASIL, 2009b).

No teste de frio foram utilizadas 100 sementes por tratamento, tendo como substrato de papel germitest na forma de rolo umedecido com água destilada na proporção de 2,5 vezes o peso do papel. Estes rolos foram mantidos a $5^{\circ} \mathrm{C}$ (geladeira) durante 7 dias. Após esse período, os rolos foram transferidos para a câmara de germinação com temperatura alternada $20^{\circ} \mathrm{C}$ por $8 \mathrm{~h}$ e $30^{\circ} \mathrm{C}$ por $16 \mathrm{~h}$, durante cinco dias. Ao final deste período foram contabilizadas somente as sementes que emitiram radícula e o resultado expresso em porcentagem.

Na emergência a campo 100 sementes por tratamento foram semeadas em bandejas plásticas utilizando areia lavada como substrato. O teste foi desenvolvido em telado com avaliação das plântulas emergidas até a estabilização da emergência, ocorrida 11 dias após a implantação do teste, e o resultado expresso em porcentagem de plântulas emergidas.

$O$ índice de velocidade de emergência foi realizado juntamente com o teste de emergência, sendo quantificado o número de plântulas emergidas diariamente até a estabilização da emergência de plântulas, e com esses valores foram determinados os índices segundo a expressão proposta por Maguire (1962).

$\mathrm{Na}$ matéria seca das plântulas 100 sementes por tratamento foram submetidas ao teste de germinação (BRASIL, 2009b) similar ao mencionado acima. Cinco dias após a instalação do teste, foram selecionadas ao acaso 40 plântulas normais, sem os cotilédones, por tratamento e submetidas à estufa sob temperatura de $70^{\circ} \mathrm{C}$ por $24 \mathrm{~h}$. Após esse período as plântulas foram pesadas em balança de precisão com 4 casas decimais e o resultado expresso em $\mathrm{g}$ por plântula. 
E para o Índice da Frequência de Microrganismos (IFM) 100 sementes por tratamento foram dispostas em placas de Petri sobre camada de papel de filtro umedecido, mantendo distância de $1 \mathrm{~cm}$ entre as sementes. As placas de Petri foram dispostas sob lâmpadas fluorescente branca com fotoperíodo de $12 \mathrm{~h}$ pelo período de 8 dias na temperatura de $20^{\circ} \mathrm{C}$ (BRASIL, 2009a). Após esse período os tratamentos foram avaliados visualmente sendo dada a cada semente notas de 0 a 5 , sendo a nota 0 indicativo de ausência de microrganismos, a nota 5 para semente totalmente preenchida com microrganismos e as demais para as classes intermediárias a estas e de forma crescente na quantidade de microrganismos. A partir dessas notas foi calculado o índice da frequência de microrganismos pela fórmula IFM $=\Sigma$ (Nota $\mathrm{x}$ frequência) / n. ${ }^{\circ}$ total de sementes, adaptado de Malavolta et al. (2007).

$\mathrm{O}$ delineamento experimental foi inteiramente casualizado com quatro repetições. As variáveis foram submetidas à análise de variância e as médias comparadas pelo teste de Scott-Knott, a 5\% de probabilidade, utilizando o programa estatístico Sisvar ${ }^{\circledR}$ (FERREIRA, 2011) para análise dos dados. A frequência utilizada no índice de frequência de microrganismos foi calculado utilizando o programa Excel ${ }^{\circledR}$.

\section{RESULTADOS E DISCUSSÃO}

Os parâmetros germinação e vigor, que determinam a qualidade fisiológica das sementes, não apresentaram diferença significativa, independente do tratamento utilizado em tomate cultivar Super Marmande (Tabela 1), indicando que a utilização do produto químico ou concentrações de até $200 \mathrm{~g}$ de extrato aquoso da folha do neem não alteraram a capacidade das sementes em germinar, nem a capacidade delas se tornarem plântulas vigorosas, ficando evidente que a qualidade fisiológica inicial das sementes $\left(0 \mathrm{~g} \mathrm{~L}^{-1}\right)$ foi mantida após tratadas, resultado semelhante ao observado em sementes de milho (Zea mays L.) e feijão (Phaseolus vulgaris L.) tratadas com o mesmo extrato aquoso (RICKLI et al., 2011).

Tabela 1. Qualidade fisiológica (germinação e vigor) e sanitária (IFM) de sementes de tomate cultivar Super Marmande submetidas a diferentes tratamentos (Thiran e extratos aquosos de folha de neem).

\begin{tabular}{cccccccc}
\hline \multirow{2}{*}{$\begin{array}{c}\text { Tratamento } \\
\left(\mathrm{g} \mathrm{L}^{-1}\right)\end{array}$} & $\begin{array}{c}\text { Germinação } \\
(\%)\end{array}$ & $\begin{array}{c}\text { Primeira } \\
\text { contagem } \\
(\%)\end{array}$ & $\begin{array}{c}\text { Frio } \\
(\%)\end{array}$ & $\begin{array}{c}\text { Emergência } \\
(\%)\end{array}$ & $\begin{array}{c}\text { Índice de } \\
\text { Velocidade de } \\
\text { Emergência }\end{array}$ & $\begin{array}{c}\text { Matéria Seca } \\
\text { das plântulas } \\
\left(\mathrm{g} \mathrm{plântula}^{-1}\right)\end{array}$ & $\begin{array}{c}\text { Índice da } \\
\text { Microequerncia de } \\
(\text { IFM) }\end{array}$ \\
\hline Thiran & $80 \mathrm{a}$ & $50 \mathrm{a}$ & $67 \mathrm{a}$ & $93 \mathrm{a}$ & $5,40 \mathrm{a}$ & $1,0681 \mathrm{a}$ & $0,91 \mathrm{a}$ \\
0 & $79 \mathrm{a}$ & $64 \mathrm{a}$ & $75 \mathrm{a}$ & $93 \mathrm{a}$ & $5,29 \mathrm{a}$ & $1,0448 \mathrm{a}$ & $2,00 \mathrm{~b}$ \\
40 & $75 \mathrm{a}$ & $73 \mathrm{a}$ & $62 \mathrm{a}$ & $86 \mathrm{a}$ & $5,00 \mathrm{a}$ & $1,0773 \mathrm{a}$ & $2,16 \mathrm{~b}$ \\
80 & $84 \mathrm{a}$ & $74 \mathrm{a}$ & $64 \mathrm{a}$ & $95 \mathrm{a}$ & $5,92 \mathrm{a}$ & $1,0594 \mathrm{a}$ & $2,03 \mathrm{~b}$ \\
120 & $86 \mathrm{a}$ & $76 \mathrm{a}$ & $76 \mathrm{a}$ & $89 \mathrm{a}$ & $5,10 \mathrm{a}$ & $1,0632 \mathrm{a}$ & $1,92 \mathrm{~b}$ \\
160 & $81 \mathrm{a}$ & $81 \mathrm{a}$ & $69 \mathrm{a}$ & $89 \mathrm{a}$ & $5,03 \mathrm{a}$ & $1,0592 \mathrm{a}$ & $1,46 \mathrm{a}$ \\
200 & $81 \mathrm{a}$ & $74 \mathrm{a}$ & $53 \mathrm{a}$ & $92 \mathrm{a}$ & $5,89 \mathrm{a}$ & $1,0646 \mathrm{a}$ & $1,44 \mathrm{a}$ \\
\hline $\mathrm{CV}(\%)$ & 7,67 & 17,85 & 19,2 & 4,70 & 14,50 & 2,49 & 6,30 \\
\hline
\end{tabular}

*Valores seguidos por letras iguais na coluna não diferem significativamente pelo teste de Scott-Knott $(\mathrm{p} \leq 0,05)$.

A conservação da qualidade fisiológica das sementes de tomate após serem tratadas com extrato aquoso da folha de neem foi um resultado relevante (Tabela 1), pois o tratamento é realizado para agir sobre o contaminante e não sobre a semente, garantindo a perpetuação vigorosa da espécie. Porém, nem sempre a semente tratada fica isenta de biomoléculas denominadas aleloquímicas (metabólitos secundários) contidas em extratos vegetais que prejudicam o comportamento da semente, como foi observado em alface [Lactuca sativa L.], soja [Glycine max (L.) Merr.](RICKLI et al., 2011) e feijão [P. vulgaris] (SILVA et al., 2007) que apresentaram redução no potencial germinativo ao serem tratadas com neem.

$\mathrm{O}$ efeito prejudicial à semente ocorre com base na concentração dos metabólitos secundários presentes no extrato vegetal, pois baixas concentrações dos metabólitos no extrato não o tornam aleloquímico a semente (MAIRESSE et al., 2007). Porém, mesmo não tendo sido mensurada neste trabalho a quantidade de metabólitos presentes nos extratos aquosos de neem como triterpenóides (azadiractina), geduninas, nimbinm, liminóides, dentre outras substâncias (NEVES et al., 2003), e sabendo que o método de extração aquoso é o que possibilita menor extração de metabólitos quando comparado a extração com óleo ou álcoois (ARAÚJO et al., 2014), os resultados da qualidade fisiológica (Tabela 1) expressam que provavelmente as substâncias alelopáticas do extrato aquoso da folha do neem não estavam presentes em concentrações suficientes para o tornarem aleloquímico a semente de tomate.

Foi identificada diferença significativa na variável índice de frequência de microrganismos (Tabela 01), parâmetro relacionado à qualidade sanitária das sementes, observando que sementes isentas de tratamento $\left(0 \mathrm{~g} \mathrm{~L}^{-1}\right)$ e nas concentrações de 40 a $120 \mathrm{~g} \mathrm{~L}^{-1}$ apresentavam contaminantes, que foram significativamente reduzidos utilizando extrato de folha de neem nas concentrações de 160 e $200 \mathrm{~g} \mathrm{~L}^{-1}$, eficiência semelhante a observada utilizando-se o tratamento químico (Thiran).

A eficiência sanitária dos extratos de folha de neem nas concentrações entre 160 e $200 \mathrm{~g} \mathrm{~L}^{-1}$ (Tabela 1) atuaram na redução dos contaminantes de sementes de tomate, provavelmente por apresentarem a dose mínima de metabólitos necessária para controlar os microrganismos (ALMEIDA et al., 2009; GONÇALVES et al., 2016).

$O$ resultado observado nos extratos de neem nas concentrações entre 40 a $120 \mathrm{~g} \mathrm{~L}^{-1}$, que não conseguiram reduzir a quantidade de microrganismos (Tabela 1), foi importante para identificar que os microrganismos presentes nas sementes do tomate eram apenas contaminantes e não patógenos (PESKE et al., 2012), ou seja, eram microrganismos inofensivos à semente do tomate, pois mesmo presentes nas sementes eles não prejudicaram sua qualidade fisiológica como mencionado anteriormente.

Mesmo os microrganismos encontrados nas sementes deste trabalho não sendo patógenos, é recomendado para a 
produção orgânica o tratamento de sementes de tomate com concentrações que os reduzam, como ocorreu com 160 e 200 $\mathrm{g} \mathrm{L}^{-1}$ do extrato aquoso da folha de neem (Tabela 01), pois no sistema orgânico não é tolerado presença de contaminantes (LOPES, 2014), visto que o contaminante não eliminado pode ser transportado para uma área de produção orgânica via semente e ser patogênico para outra cultura vegetal (PESKE et al., 2012).

Não foi possível classificar os microrganismos presentes nas sementes e consequentemente os que o extrato de folha de neem consegue controlar, pois alguns metabólitos secundários afetam de forma distinta aos diversos microrganismos (ARAUJO et al., 2014).

\section{CONCLUSÃO}

O uso do extrato aquoso da folha de neem nas doses de 160 a $200 \mathrm{~g} \mathrm{~L}^{-1}$ é eficiente no tratamento de sementes de tomate Super Marmande.

\section{REFERÊNCIAS}

ALMEIDA, T. F.; CAMARGO, M.; PANIZZI. R. C. Efeito de extratos de plantas medicinais no controle de Colletotrichum acutatum, agente causal da flor preta do morangueiro. Summa Phytopathol., v.35, n.3, p.196-201, 2009.

AMADIOHA, A. C. Controlling rice blast in vitro and in vivo with extracts Azadirachta indica. Crop Protection, v.19, n.5, p.287-290, 2000. 10.1016/S0261-2194(99)00080-0

AMADIOHA, A. C.; UCHENDU, P. N. Post harvest control of tomato fruit rot caused by Fusarium solani with extracts of Azadirachta indica. African Journals online, v.15, n.1, 2003. 10.4314/dai.v15il.15629

ARAÚJO, E. R.; HARAND, W.; LIMA, I. C; DIAS, F. C. R.; SANTANA, A. A. D.; CARVALHO, R. R.C.; LARANJEIRA, D. Extratos de Piper marginatum e Azadirachta indica no controle de Colletotrichum scovillei em pimentão. Pesquisa agropecuária brasileira, v.49, n.2, p.88-94, 2014.

BHONDE, S. B.; DESHPANDE, S. G.; SHARMA, R. N. In vitro evaluation on inhibitory nature of some Neem formulations against plant pathogenic fungi. Hindustan Antibiot., v.41, p.22-24, 1999.

BRASIL. Ministério da Agricultura, Pecuária e Abastecimento. Instrução Normativa $n^{\circ} 17$, de 18 de junho de 2014. Altera artigos da IN 46. Diário Oficial da União; Poder Executivo, 2014.

BRASIL. Ministério da Agricultura, Pecuária e Abastecimento. Instrução Normativa ${ }^{\circ} 64$, de 19 de dezembro de 2008. Aprovar o Regulamento Técnico para os Sistemas Orgânicos de Produção Animal e Vegetal. Diário Oficial da União; Poder Executivo, 2008.

BRASIL. Manual de Análise Sanitária de Sementes. Brasília: MAPA/ACS, 2009a. 200p.

BRASIL. Regras para análise de sementes. Brasília: MAPA/ACS. 2009b. 399p.

CHATTOPADHYAY, C. Yield loss attributable to alternaria bligh of sunflower (Helianthus annuus L.) in India and some potentially effective control measures. International Journal of Pest Management, v.45, n.1, p.15-21, 1999. $10.1080 / 096708799227996$

FERREIRA, D. F. Sisvar: a computer statistical analysis system. Ciência e agrotecnologia, v.35, n.6, p.1039-1042, 2011.

GONÇALVES, A. P. P.; VIEIRA, G. D.; CUNHA, P. N. A.; KISSLER, T. V. L.; HERNÁNDEZ, A. E. F.; TELES, C. B. G. Caracterização fitoquímica e atividade antimicrobiana de extratos de Solanum subinerme (Solanaceae). Revista Brasileira Pesquisa Saúde, v.18, n.2, p.8-16, 2016.

LOPES, C. A. Hortaliças orgânicas só podem ser produzidas com sementes orgânicas?, 2014. Disponível em: <http://www.embrapa.br/busca-de-noticias/-

/noticia/3234227/hortalicas-organicas-so-podem-serproduzidas-com-sementes-organicas>. Acesso em: 14 set. 2016.

MAGUIRE, J. D. Apeed of germination-aid in selection and evalution for seedling emergence and vigor. Crop Science, v.2, n.2, p.176-177, 1962.

MAIRESSE, L. A. S.; COSTA, E. C.; FARIAS, J. R.; FIORIN, R. A. Bioatividade de extratos vegetais sobre alface (Lactuca sativa L.). Revista da FZVA, v.14, n.2, p. 1-12. 2007.

Malavolta, V. M. A.; SOligO, E. A.; DIAS, D. D.; AZZINI, L. E.; BASTOS, C. R. Incidência de fungos e quantificação de danos em sementes de genótipos de arroz. Summa Phytopathol., v.33, n.3, p.280-286, 2007.

MELO, P. C. T.; MELO, A. M. T.; NASCIMENTO, M. M.; FREITAS, R. A. Produção de sementes de tomate. In: NASCIMENTO, W.M. (ed.). Produção de sementes de hortaliças. v2. Brasília: Embrapa, 2014. p.235-263.

NEVES, B. P.; OLIVEIRA, I. P.; NOGUEIRA, J. C. M. Cultivo e utilização do nim indiano. Embrapa Arroz e FeijãoCircular Técnica 62 (INFOTECA-E), 2003.

OWOLADE, O. F.; AMUSA, A. N. ; OSIKANLU, Y. O. K. Efficacy of certain indigenous plant extracts against seedborne infection of Fusarium moniliforme on maize (Zea mays L.) in south western Nigeria. Cer.Res. Commun, v.28, p.32332, 2000.

PESKE, S. T.; VILlELA, F. A.; MENEGHELlO, G. E. Sementes: fundamentos científicos e tecnológicos. Pelotas: Editora Universitária UFPel, 2012. 573p.

RICKLI, H. C.; FORTES, A. M. T.; SILVA, P. S. S.; PILATTI, D. M.; HUTT, D. R. Efeito alelopático de extrato aquoso de folhas de Azadirachta indica A. Juss. em alface, soja, milho, feijão e picão-preto. Semina, v.32, n.2, p.473484, 2011.

ROSSETTO, C. A. V.; LIMA, T. M.; NAKAGAWA, J. Avaliação da aplicação de fungicida e do condicionamento osmótico durante o armazenamento de sementes de tomate. Revista Brasileira de Sementes, v.23, n.2, p.229-235, 2001.

SILVA, J. P.; CROTTI, A. E. M.; CUNHA, W. Antifeedant and allelopathic activities of the hydroalcoholic extract obtained from Neem (Azadirachta indica) leaves. Brazilian Journal of Pharmacognosy, v.17, n.4, p.529-532, 2007. 10.1590/S0102-695X2007000400009 